\title{
Ultrafast laser scanning cellular microscopy by spatiotemporally encoded virtual sources
}

Wenwei Yan

Jianglai $\mathrm{Wu}$

Kenneth K. Y. Wong

Kevin K. Tsia 


\section{Ultrafast laser scanning cellular microscopy by spatiotemporally encoded virtual sources}

Wenwei Yan, Jianglai Wu, Kenneth K.Y. Wong and Kevin K. Tsia

Department of Electrical and Electronic Engineering, The University of Hong Kong

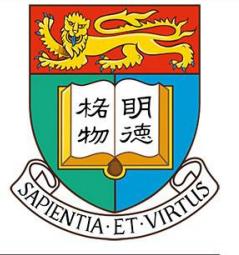

Introduction We report a new type of all-optical ultrafast laser-scanning microscopy (at a line-scan rate of $20 \mathrm{MHz}$ ) based on a phenomenon called free-space angular-chirp-enhanced delay (FACED). It results in the generation of a reconfigurable array of spatiotemporally encoded virtual pulsed sources, which acts as a scanning laser beam. We demonstrate its application in high-throughput multivariate image-based single-cell analysis $(10,000 \mathrm{cells} / \mathrm{sec})$.

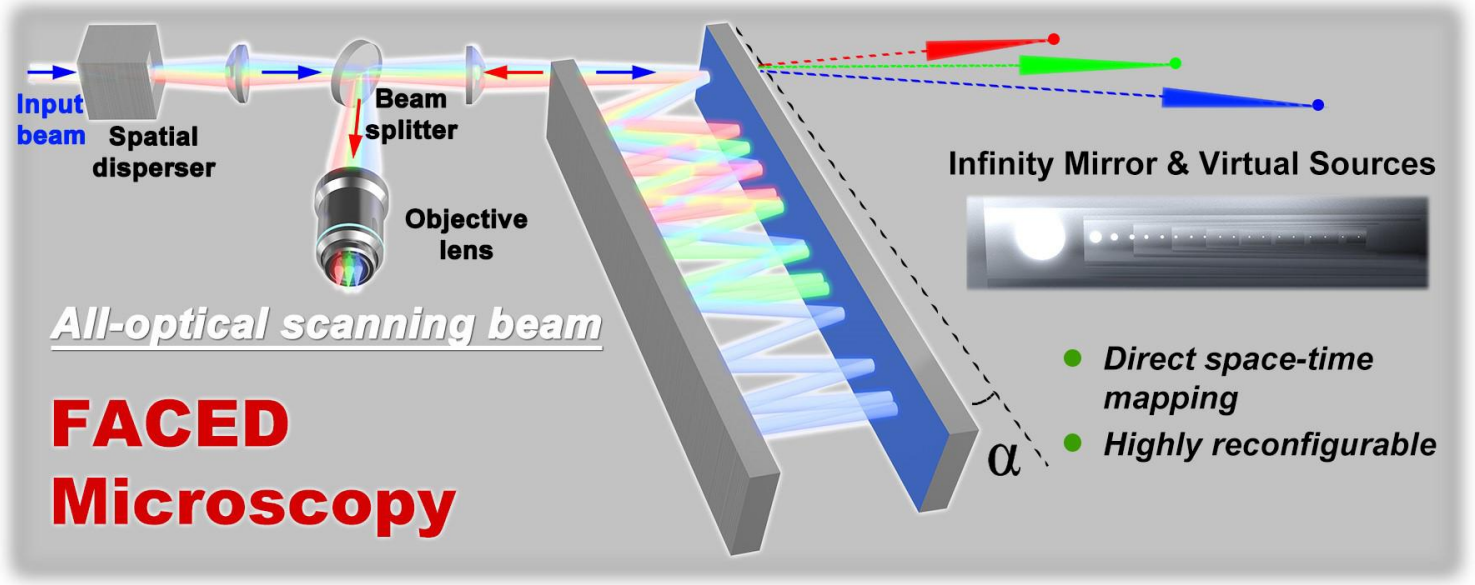

Spatial \& temporal line-scan profile

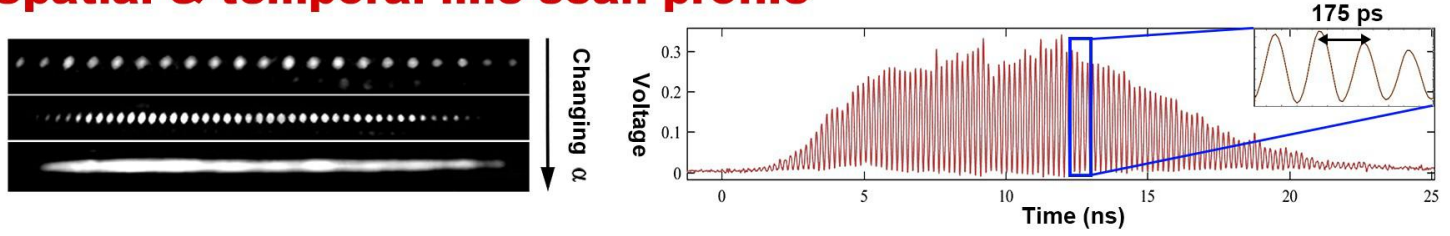

\section{From ultrafast single-cell imaging to analysis}
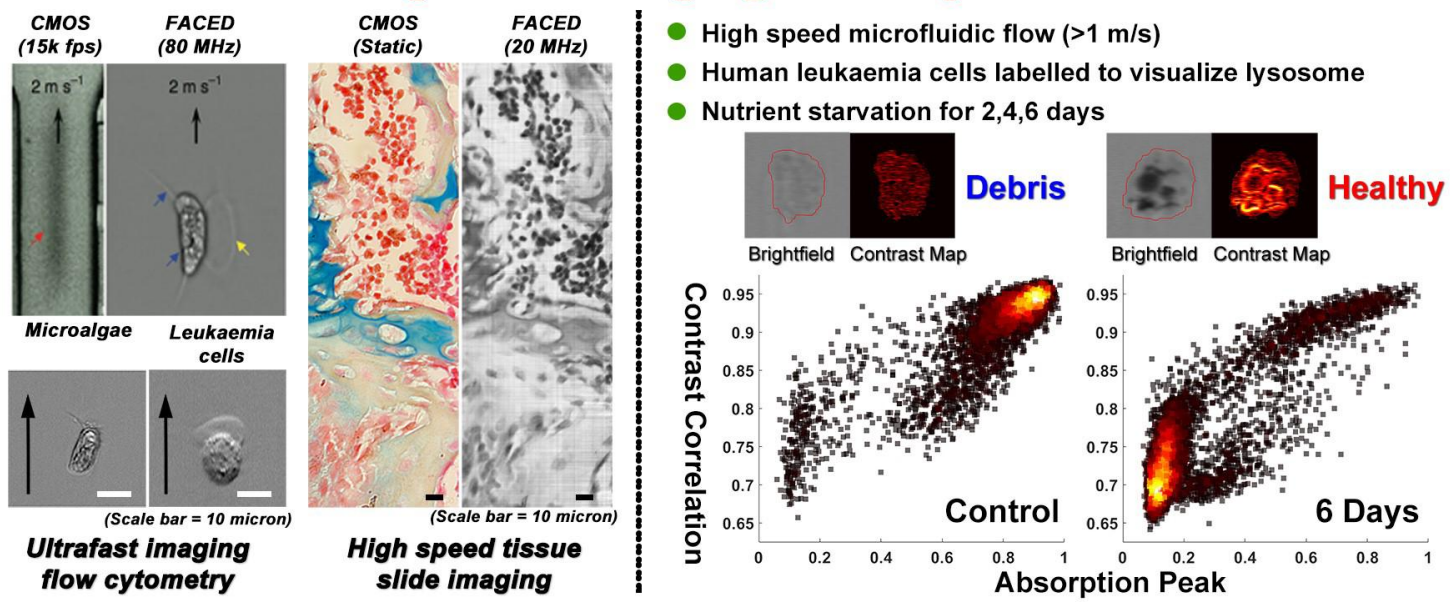

References:

[1] Wu, J., et al., "Ultrafast laser-scanning time-stretch imaging at visible wavelengths," Light: Science \& Applications 6, e16196 (2017).

International Conference on Biophotonics V, edited by David D. Sampson, Dennis L. Matthews, Jürgen Popp, Halina Rubinsztein-Dunlop, Brian C. Wilson, Proc. of SPIE Vol. 10340, 103401A · C 2017 SPIE

CCC code: $1605-7422 / 17 / \$ 18 \cdot$ doi: $10.1117 / 12.2270546$ 